\title{
Editor's Essay: Moving beyond Western Corporate Perspectives: On the Need to Increase the Diversity of Risk and Crisis Communication Research
}

\author{
Audra Diers-Lawson ${ }^{1}\left(\left[\right.\right.$ and Florian Meißner ${ }^{2}$ () \\ 1. School of Public Relations and Journalism, Leeds Business School, Leeds Beckett \\ University, Leeds, GB \\ 2. Media Faculty, Macromedia University of Applied Sciences, Cologne, Germany
}

\section{ABSTRACT}

The field of crisis and risk communication research has experienced significant growth and increasing institutionalization in the past decades. However, there are still geographic and perspective blind spots. Up to date, by far the most research focuses on the U.S.; non-Western perspectives remain marginal. Moreover, the focus on organizational crises still clearly dominates. We therefore call for more research better reflecting the global environment and diverse crisis and risk contexts in which our field can make contributions. This argument is supported by the current pandemic mandating cross-cultural and multi-perspective approaches.

KEYWORDS: crisis communication, risk communication, internationalization, comparative research

In a reflection on his own experience in practice as a risk communication consultant to the WHO Health Emergencies Programme, Ben Duncan makes the argument that in his view crisis communication had evolved from being "corporate public relations" to a life-saving intervention (Diers-Lawson, 2020). In the last several years, we have seen good evidence of this evolution with crisis communication research and theory applied

CONTACT Audra Diers-Lawson (D) - E-mail: audra.lawson@leedsbeckett.ac.uk • School of Public Relations and Journalism • Leeds Business School • Leeds Beckett University • Rose Bowl, Portland Crescent • Leeds, LS1 3HB

Copyright 2021 Authors. Published under a Creative Commons Attribution 4.0 International (CC BY-NC-ND 4.0) license. 
in the context: of post-Ebola epidemics in Africa (Tambo et al., 2017); communication challenges of terror crises (Ruggiero \& Vos, 2015); natural disasters (Romascanu et al., 2020) including the role of social media during disasters (Dahal et al., 2020); industrial disasters (Utz et al., 2013) and other types of emergencies (Wukich \& Mergel, 2015).

We are also seeing the field broaden in its geographic reach with research published addressing crises from different geographic and cultural experiences such as exploring the role of crisis and social media for social movements in Mexico (Sandoval-Almazan \& Gil-Garcia, 2014); food safety in New Zealand (Galloway et al., 2019); news coverage of terrorism in Norway (Falkheimer \& Olsson, 2015); and an exploration of stakeholder engagement affecting the hospitality and tourism industry in multiphase disaster management in Africa (Granville et al., 2016). Despite these evolutions in the field broadening its scope beyond corporate-focused public relations, increasingly representing diverse geographic and cultural experiences, we acknowledge that there is still work to do. As we look ahead to our tenure as the editorial staff over the next two volumes, our aim is to continually critically reflect on the field and identify the areas of development needed as crisis and risk communication continues to be institutionalized. This is precisely what Seeger (2018) and Liu (2019) set out as priorities in establishing and developing this journal, and we aim to continue. We also argue that as the world faces increasing levels of uncertainty attributable to mega-crises like the COVID-19 pandemic or pan-regional and localized crises like the 2020 fires in Australia; continued refugee crisis in North Africa, the Middle East, and Europe; Brexit in the UK; water crises affecting countries across Latin America; or social and political volatility in the United States it is imperative that our field continues to broaden its scope to explore, understand, and help manage the problems affecting people around the world.

Therefore, in this editorial we:

1. Critically reflect on the growth and institutionalization of crisis and risk communication 
2. Address existing geographic and thematic biases in crisis and risk communication

3. Call for more research better reflecting the global environment and diverse crisis and risk contexts in which our field can make contributions

4. Connect the contributions of this issue to the continued development of the field.

\section{Growth and Institutionalization of Crisis and Risk Communication}

Of course, the COVID-19 pandemic has underscored the importance of crisis and risk communication and, as a field, we are working to make sense of the contributions that we have and can make to that field with our research-like the journal's forthcoming special issue on the COVID-19 pandemic edited by Dr. Yan Jin. However, before the COVID-19 pandemic, the field of crisis and risk communication was showing strong evidence of its global growth and institutionalization. We are a diverse and multidisciplinary field that is regularly published in hundreds of different journals using theories ranging from those developed for crisis and risk communication to traditional persuasion and communication, management, health, educational, cultural, media, and leadership theories to name just a few (Diers-Lawson, 2020). During specialty conferences like the bi-annual crisis series sponsored by the European Communication, Research, and Education Association or the annual International Crisis and Risk Communication Conference hosted by the University of Central Florida, in 2019 and 2020 colleagues from at least 20 different countries and all continents participated and presented their work. Across the journals publishing crisis communication research, there are more than 55 countries represented across the continents (Diers-Lawson, 2020). However, we need to acknowledge the field has both geographic and thematic bias and this is important to address both as a field and also as a journal. 


\section{Geographic and Perspective Bias}

While the participation in the field, its global growth, and its increasing institutionalization and recognition is certainly worth celebrating we also know that there is more work to do to ensure the published research reflects more of the reality of the broad global participation we can evidence. For example, as DiersLawson (2020) documented there are significant geographic and perspective biases in the field that are also reflected in this journal as well.

\section{Geographic Bias}

Much of the early and foundational research in crisis communication came from the United States, spreading to Europe, and then Asia-especially China. In fact, from the 1950 s to 2015 there was a disproportionate representation of the United States with about $67 \%$ of journal-based research published that was focused on American crises, organizations, or contexts (Diers-Lawson 2017; 2020). While the trends are changing and generally the field is seeing more research published in journals, books, and collections from other countries, there remains a focus on industrialized countries and especially the "Western" perspective. The global South is underrepresented. This is also true of the Journal of International Crisis and Risk Communication Research as well. In reviewing articles published across the first three volumes that used data, while the journal demonstrates more proportional geographic diversity compared to the whole field, we still have work to do to reduce the bias on crisis in industrialized countries and especially the United States (see Table 1).

\section{Perspective Bias}

Though the field of crisis and risk communication is multidisciplinary, most of the research has been published largely in traditional public relations, communication, management, and social science journals (Diers-Lawson, 2020). Not surprisingly, the field often focuses on organizational or public relations perspectives, 
TABLE 1 Geographic Distribution of Crisis Communication Research (by percentage)

\begin{tabular}{|c|c|c|}
\hline Region & $\begin{array}{c}\text { Crisis Communication } \\
1950-2015^{1}\end{array}$ & $\begin{array}{l}\text { JICRCR } \\
\text { Vol 1-3 }\end{array}$ \\
\hline North America & $67.8 \%$ & $64 \%$ \\
\hline Europe & $18.6 \%$ & $11 \%$ \\
\hline Asia \& Australasia & $13.4 \%$ & $11 \%$ \\
\hline Africa & $1.2 \%$ & $6 \%$ \\
\hline $\begin{array}{l}\text { Central \& South America, } \\
\text { Caribbean }\end{array}$ & $.9 \%$ & $6 \%$ \\
\hline Middle East & $.9 \%$ & $3 \%$ \\
\hline
\end{tabular}

Notes: ${ }^{1}$ Data about the field taken from Diers-Lawson, 2020

${ }^{2}$ North America includes $66.9 \%$ from the U.S. and .9\% from Canada

thus it has an organizational bias. The organizational bias often means that the objectives for analysis is how to better the organization's ability to respond to a crisis, protect its reputation, and minimize the impact of the crisis on the organization. By extension, those interests can connect to interests of external stakeholders like media, politics, or health. This is also true in the context of the Journal of International Crisis and Risk Communication Research; however, the journal has developed a stronger balance between the organizational bias, stakeholder-focused research, hybrid or social media research, and non-organizational crises (see Table 2). We argue that crisis and risk communication has meaningful contributions to make to understanding and addressing "wicked" or persistent problems that are affecting people globally ranging from climate change, disasters, injustice, economic deprivation, globalization, politics, health epidemics and pandemics, as well as specific organizational crises. As the field continues to institutionalize, we argue that it should focus on studying issues of risk and crisis more than being a field that studies organizations in crisis. Especially important in this regard is the role of the broad media environment in understanding and influencing crisis and risk communication. 
TABLE 2 Perspective Focus in the Journal of International Crisis and Risk Communication Research (by percentage)

\begin{tabular}{|l|c|}
\hline Broad Perspectives & JICRCR Vol 1-3 \\
\hline Organizational/Corporate Focused & $42 \%$ \\
\hline Media Focused & $6 \%$ \\
\hline Stakeholder Focused & $19 \%$ \\
\hline Hybrid (Social Media) & $10 \%$ \\
\hline Non-Organizational Crises (e.g., health, environment) & $23 \%$ \\
\hline
\end{tabular}

\section{Broadening the Voices and Contexts for Research in 2021-2023}

Our call for research for the next two volumes -4 and 5 -of the journal is to broaden the voices and contexts for research in crisis and risk communication. We have already broadened the editorial board, adding colleagues representing organizations in an additional seven countries, bringing the representation on the board to 17 countries from all continents. However, this is not enough, we also encourage high quality submissions reflecting the diversity of experience, geography, and research foci appropriate within crisis and risk communication research. In particular, we would invite more international or comparative research and more research reaching beyond the organizational perspective.

\section{Call for More International and Comparative Research}

As we consider the future of crisis and risk communication research, we posit three arguments for the value of increasingly international and comparative research. First, the field will improve its theory building when existing theories are applied in new cultural contexts. For example, in the first three volumes, the Journal of International Crisis and Risk Communication Research published $14 \%$ of multinational comparisons, which provided important analysis, for example. about how different countries communicate risk about crisis and war (Petridou et al., 2019). These types of comparisons provide stronger understanding of risk and crisis as 
culture-sensitive concepts. However, we would encourage more of these comparisons over the next two volumes.

Second, expanding our understanding of different types of crisis across cultural and national settings provides epistemological value as well. There is no doubt that in the years to come there will be many pieces written about Trump's America and about the ways that disproportionately negative effects of the pandemic have been felt on the poor and disenfranchised populations around the world. Similarly, there is a fundamental need to deepen research and understanding of crisis and risk communication across the global South-in particular, there is a fundamental dearth of research relevant to Central and South America and Africa in our field and this needs to improve. However, geographic and cultural blind spots occur even in North America, where crisis and risk communication research amongst indigenous communities is virtually nonexistent. Likewise, in Europe there are blind spots as well. For example, both Scotland and Catalonia have independence movements whose arguments for independence are cultural, are rooted in colonialism, deeply held identities, and where crises like Brexit and the pandemic bring to the fore inequalities and challenges within the countries. Moreover, exploration of these from the context of risk and crisis would explore the political and complex contexts and provide a deepening of our understanding of crisis and risk.

Third, it seems clear that more international and comparative research would provide important practical lessons to be applied in crisis and risk communication research. For example, Asia has seemingly more experience in managing pandemics like MERS and SARS and during the COVID-19 pandemic has been more successful in suppressing the virus compared to all other regions (see Figure 1), including Europe and North America (see Figure 2), which would suggest there are critical practical lessons in crisis and risk communication that should have already been learned, but were not. In looking ahead to future global crises, a stronger international and comparative approach in crisis and risk communication could improve the base level knowledge of those managing the crises. 


\section{FIGURE 1 Regional Comparison of COVID-19 Deaths}

\section{Total confirmed COVID-19 deaths}

Limited testing and challenges in the attribution of the cause of death means that the number of confirmed deaths may not be an accurate count of the true number of deaths from COVID-19.

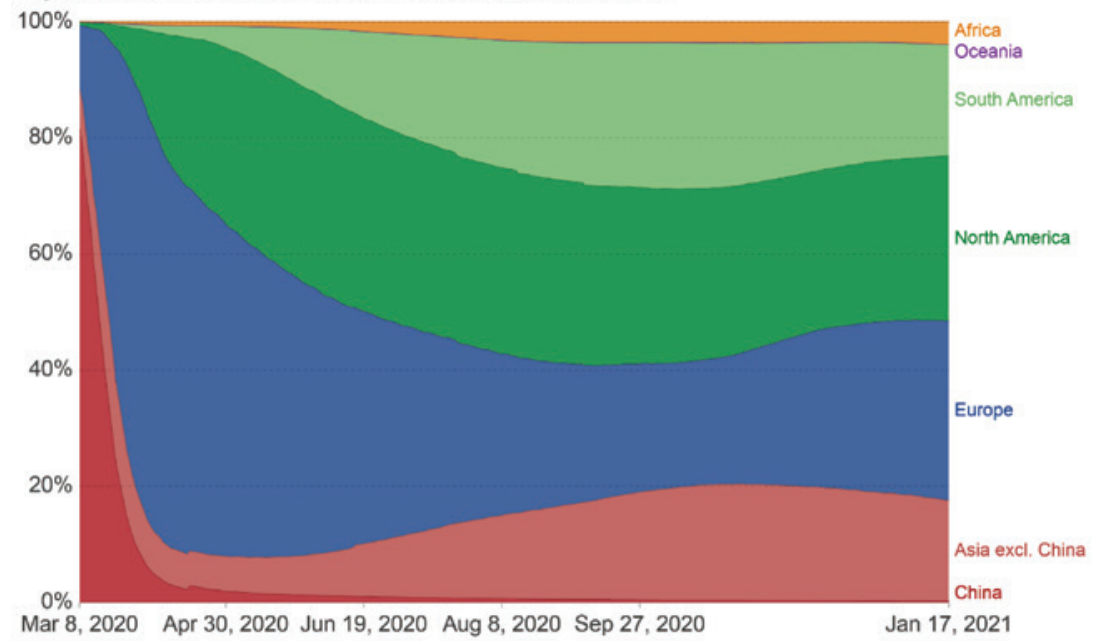

Source: Johns Hopkins University CSSE COVI-19 Data - Last updated 18 January, 06:02 (London time)

OurWorldinData.org/coronavirus * CC BY

\section{FIGURE 2 COVID-19 Deaths Comparison between Select Asian and Western Countries}

Cumulative confirmed COVID-19 deaths

Limited testing and challenges in the attribution of the cause of death means that the number of confirmed deaths may not be an accurate count of the true number of deaths from COVID-19.

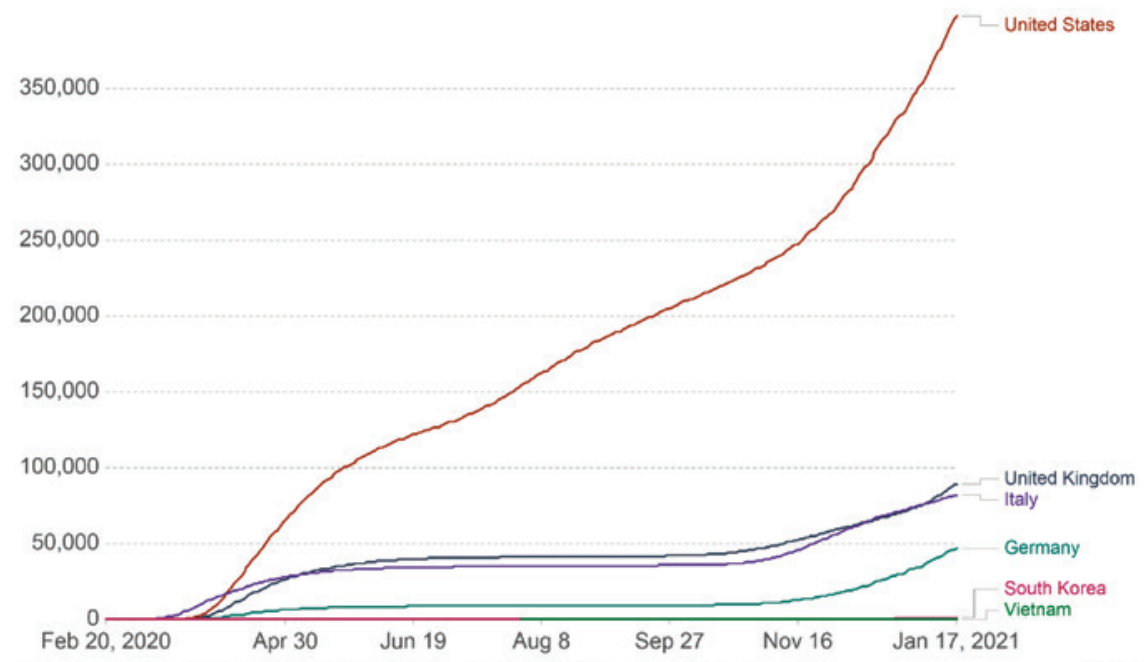

Source: Johns Hopkins University CSSE COVID-19 Data - Last updated 18 January, 06:02 (London time) 


\section{Call for Research Looking Beyond the Organizational Perspective}

In considering crisis and risk communication research, there will always be a need for research and theory development that focuses on the organizational context; addressing, for example, issues of responding effectively to crises in order to protect an organization's reputation, objectives, and stakeholders. As such, we strongly support the Journal of International Crisis and Risk Communication's relative excellence in publishing research across multiple perspectives including stakeholder and social media. However, we would encourage more research on non-organizational crises (e.g., health or political crises). We would also welcome more research on the broad role of the media environment's contribution to crisis and risk communication as this has been the perspective least explored in the previous three volumes. For instance, important yet understudied questions include: What is the role of media systems and journalism cultures in shaping the discourse on risk and crisisand how is it affected by ad hoc publics and misinformation on social media? However, more than just considering traditional domains of communication research, we would also encourage the exploration of crisis and risk communication from genuinely multidisciplinary perspectives that might join computer scientists, the medical or scientific research communities, political expertise, or certainly sector-specific research providing insights into the communicative needs in crisis contexts.

\section{Connecting the Contributions of Volume 4, Issue 1 to Our Calls for Research}

The five pieces in this volume reflect an excellent starting point in meeting the calls for the impact and diversity in perspective, theme, and geography that we have discussed to this point. Each of the articles in this volume develop our understanding of the stakeholder perspective in different ways. Jin, Lee, Liu, Austin, and Kim's analysis of infectious disease threat assessment by college students is a timely contribution as universities around the world are trying to manage the pandemic's effects on their campus 
communities and delivery of courses. Jong and Brataas's piece explores the importance of treating victims of crises as stakeholders with valuable interests in the resolution of crises of different types. Oh, Yoo, and Owlett take an organizational perspective, but one that focuses on the importance of using social media to focus on person centered messages in public relations. Miller, Collins, Neuberger, Todd, Sellnow, and Bouteman's systematic review of the global CERC literature provides insights into the theory's development and application that provides reflection and a future orientation on how crisis, emergency, and risk communication can be developed into the future. Finally, Jun and Jin's risk toleration scale development provides a new tool for exploring people's tolerance of health risks. Though each of these pieces provides value within the stakeholder perspective, they also connect social media, non-organizational, and organizational contexts to better explore the interconnections in crisis and risk communication research. Two of the pieces-Jong and Brataas and Miller et al.s-also represent the international or comparative perspectives we are calling for as well.

We look forward to the excellence in the submissions, appreciate our editorial board and reviewers, supporting and encouraging the growth and diversity of interest in crisis and risk communication research.

\section{ORCID}

Audra Diers-Lawson (1) https://orcid.org/oooo-0003-2584-5061 Florian Meißner (ㄱ) https://orcid.org/oooo-0002-3378-410X

\section{References}

Dahal, L., Idris, M. S., \& Bravo, V. (2020). "It helped us, and it hurt us" The role of social media in shaping agency and action among youth in post-disaster Nepal. Journal of Contingencies and Crisis Management, 28(4), online. https:// doi.org/10.1111/1468-5973.12329 
Diers-Lawson, A. (2017). Crisis communication. Oxford Research Encyclopedia of Communication. Oxford University Press. https://doi.org/10.1093/acrefore/9780190228613.013.397

Diers-Lawson, A. (2020). Crisis communication: Managing stakeholder relationships. Routledge.

Falkheimer, J., \& Olsson, E.-K. (2015). Depoliticizing terror: The news framing of the terrorist attacks in Norway, 22 July 2011. Media, War \& Conflict, 8(1), 70-85. https://doi. org/10.1177/1750635214531109

Galloway, C., Ashwell, D., Croucher, S., \& Diers-Lawson, A. (2019). Testing times: Communicating the role and uncertainty of analytical procedures in a food safety crisis. Asian Journal of Communication, 20(2), 42-58.

Granville, F., Mehta, A., \& Pike, S. (2016). Destinations, disasters and public relations: Stakeholder engagement in multiphase disaster management. Journal of Hospitality and Tourism Management, 28, 73-79. https://doi.org/10.1016/j. jhtm.2016.02.001

Liu, B. F. (2019). Editor's essay: The critical need for crisis and risk communication research. Journal of International Crisis and Risk Communication Research, 2(1), 7-11. https://doi. org/10.30658/jicrcr.2.1.1

Petridou, E., Danielsson, E., Olofsson, A., Lundgren, M., \& Große, C. (2019). If crisis or war comes: A study of risk communication of eight European Union member states. Journal of International Crisis and Risk Communication Research, 2(2), 3. https://doi.org/10.30658/jicrcr.2.2.3

Romascanu, A., Ker, H., Sieber, R., Greenidge, S., Lumley, S., Bush, D., Morgan, S., Zhao, R., \& Brunila, M. (2020). Using deep learning and social network analysis to understand and manage extreme flooding. Journal of Contingencies and Crisis Management, 28(3), 251-261. https://doi.org/10.1111/14685973.12311

Ruggiero, A., \& Vos, M. (2015). Communication challenges in CBRN terrorism crises: Expert perceptions. Journal of Contingencies and Crisis Management, 23(3), 138-148. https:// doi.org/10.1111/1468-5973.12065 
Sandoval-Almazan, R., \& Gil-Garcia, J. R. (2014). Towards cyberactivism 2.0? Understanding the use of social media and other information technologies for political activism and social movements. Government Information Quarterly, 31(3), 365378. https://doi.org/10.1016/j.giq.2013.10.016

Seeger, M. W. (2018). Answering the call for scholarship: The Journal of International Crisis and Risk Communication Research. Journal of International Crisis and Risk Communication Research, 1(1), 7-10. https://doi.org/10.30658/ jicrcr.1.1.1

Tambo, E., Chengho, C. F., Ugwu, C. E., Wurie, I., Jonhson, J. K., \& Ngogang, J. Y. (2017). Rebuilding transformation strategies in post-Ebola epidemics in Africa. Infectious diseases of poverty, 6(1), 71. https://doi.org/10.1186/s40249-017-0278-2

Utz, S., Schultz, F., \& Glocka, S. (2013). Crisis communication online: How medium, crisis type and emotions affected public reactions in the Fukushima Daiichi nuclear disaster. Public Relations Review, 39(1), 40-46. https://doi.org/10.1016/j. pubrev.2012.09.010

Wukich, C., \& Mergel, I. (2015). Closing the citizen-government communication gap: Content, audience, and network analysis of government tweets. Journal of Homeland Security and Emergency Management, 12(3), 707-735. https://doi. org/10.1515/jhsem-2014-0074 